\title{
FIXITY DEPTH OF OFFSHORE PILES IN ELASTOPLASTIC SOFT CLAY UNDER DYNAMIC LOAD
}

\author{
Anis Mohamad Ali ${ }^{1}$, Mohammad J.K. Essa ${ }^{2}$, Abdulameer Qasim Hassan ${ }^{3}$ \\ ${ }^{I}$ Civil Engineering Department, Basrah University / College of Engineering/ Basrah, Iraq \\ ${ }^{2}$ Civil Engineering Department, Basrah University / College of Engineering/ Basrah, Iraq \\ ${ }^{3}$ Department of Environment and Pollution Engineering, South Technical University/ Technical College/ Basrah, Iraq
}

\begin{abstract}
This work represents study of dynamic behavior of offshore piles embedded in elastoplastic soft clay, and estimating the fixity depth of pile. ABAQUS finite element program which used to simulate the problem. The soil was modeled in two case elastic state model and elastoplastic state model represented by cam-clay model, three dimension element used to represent the interaction between pile and soil, and laboratory tests used to getting the real properties of clayey soil and to descried interface. The results obtained developed two empirical equations used to calculate depth of pile fixity for pile embedded in elastic and elastoplastic soil respectively. Also, show the depth of pile fixity is increase about (40\%) due to change soil model from elastic to plastic, when pile embedded in elastoplastic soil its dependent on soil strength, interface properties and pile rigidity. The pile head displacement is increase about $90 \%$ while the bending moment is decease $10 \%$ at pile head.
\end{abstract}

$* * *$

\section{INTRODUCTION}

Steel pile foundations are widely used for marine structures foundations, such as offshore platforms for oil and marine and offshore wind turbines, located in offshore shallow to medium water with water depth exceed to $30 \mathrm{~m}$. The structural loads (axial, lateral and moments) are transferred from superstructure to the soil by piles [1]. Fixity depth of pile (Lf) is defined as embedded of pile length measured from the sea bed level at maximum bending moment to the point which the bending moment is begin constant along the pile. The equivalent cantilever method is a common method that is used to analyze piles subjected to the lateral load. In this method, the soil-pile interaction system is represented by cantilever element and restrained against translation and rotational at the end and neglect the soil a round pile. The equivalent fixity depth can be found by equating the lateral stiffness of the soil-pile interaction system to that of an equivalent fixed-base cantilever. The drawback of this method is that the fixity pile depth can be found depended on solutions for an elastic pile drive in elastic soil [2]. The p-y curves developed built on this theory explain that they are not unique and alteration not only with soil properties, but also with the pile properties such as the pile stiffness, pile dimensions, pile head condition, and cross section. This is considerably changed from the normal p-y curves, where the p-y curves are dependent on only the soil properties and pile diameter [3].

In this paper the elastic and elastoplastic solution for soil model is used estimated depth of pile fixity and finds the variation between the response of structure and piles when the pile embedded in elastic and elastoplastic soil.

\section{FINITE ELEMENT ANALYSES}

ABAQUS is the general-purpose computer program was used to carry out the analysis. It was used to solve engineering problems based upon the finite element method applicable to linear and nonlinear solutions [4]. ABAQUS provides both linear and nonlinear response options. The program is integrated, so linear analysis is always considered as linear perturbation analysis about the state at the time when linear analysis procedure is introduced.

\subsection{Elements Selection}

Two type of element which was used is in the program to represent the structures and soil element, the first element is beam element (B32), 3-node quadratic beam in space, this type of element have three node any node have six degree of freedom, three displacement and the other three is rotation in $\mathrm{x}, \mathrm{y}$ and $\mathrm{z}$ direction, this element used to represent the structure element and pile element. The second element is (C3D20RP), 20-node brick with pore pressure, quadratic displacement, linear pore pressure and reduced integration which is used for represent the soil element each node have three displacement in $\mathrm{x}, \mathrm{y}$ and $\mathrm{z}$. These elements are more capable and more accurate for modeling problems with curved boundaries Figure 1. [4] 

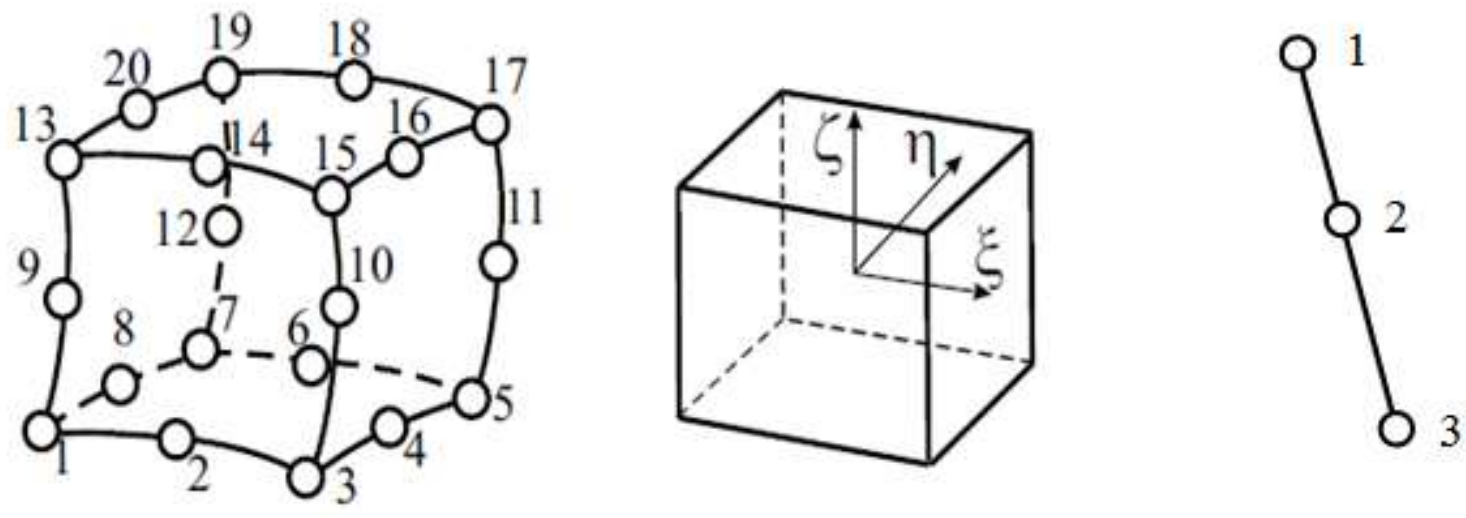

Fig 1: Type of Element used in Analysis [4]

\subsection{Interface Element}

This method used brick with 12-node translation and pore pressure element will be used to model the interface, the details of this type are shown in Figure 2. The local 1- and 2-directions are perpendicular to the width direction and, by ignored, are show in the standard ABAQUS agreement for local directions on surface. Transverse shear activity is shown
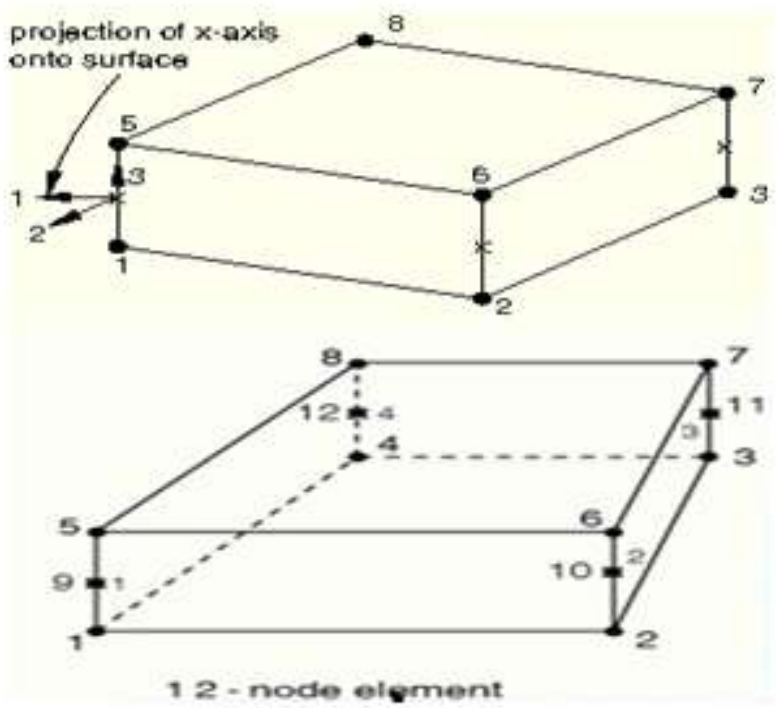

Fig 2; Three Dimensional Cohesive Elements [5]

\section{CONSTITUTIVE SOIL MODEL}

Modified cam clay model is an elasto-elastoplastic model establish on limited and simple assumption that estimate the stress-strain response of soils. At beginning the model was settled from triaxial tests documents and after that based on developed for three-dimensional stress relation. In critical state mechanics, the state of a soil sample is considered by three factors, normal stress p', shear stress q, and specific volume $v$. Under general stress situations, the normal stress, p', and the shear stress, q, calculated by used principal stresses $\sigma_{1}^{\prime}, \sigma_{2}^{\prime}$ and $\sigma_{3}^{\prime}$ as in the local 1-3 and 2-3 planes for these elements Figure 3. Shows the model of interface element between soil and pile, the ignored local directions for brick cohesive element are shown in Figure 3. The displacement of each node has three components, one in tangential $u_{x}$ and the other two in normal direction of the element $u_{y}, u_{z}$. [4, 5]

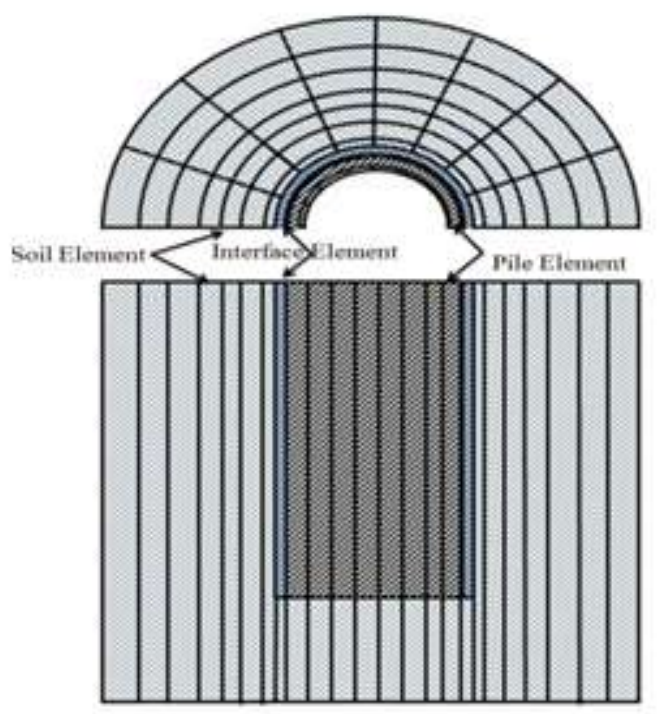

Fig 3; Three Dimensional Cohesive Elements [5]

$$
\begin{aligned}
& p^{r}=\frac{1}{3}\left(\sigma_{1}+\sigma_{2}^{r}+\sigma^{r}\right)-1
\end{aligned}
$$

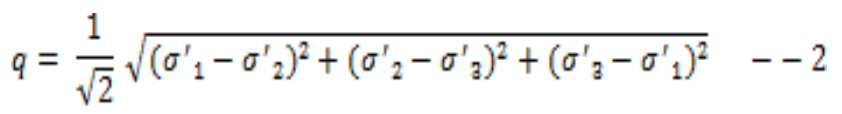

Specific volume calculated from $v=1+e$ where e is the void ration. Yield functions of modified cam clay model determined from the following equation. [5, 6]

$$
\frac{q^{2}}{p^{12}}+M^{2} \ln \left(1-\frac{p_{0}^{t}}{p^{f}}\right)=0--3
$$




\section{SOIL TESTS}

\subsection{Triaxial Test}

In a standard triaxial compression test, a tubular core model is subjected to axial load to collapse, at steady state pressure. Conceptually, the greatest value of the axial stress is representing confined compressive strength $\mathrm{Cu}$ of the model.

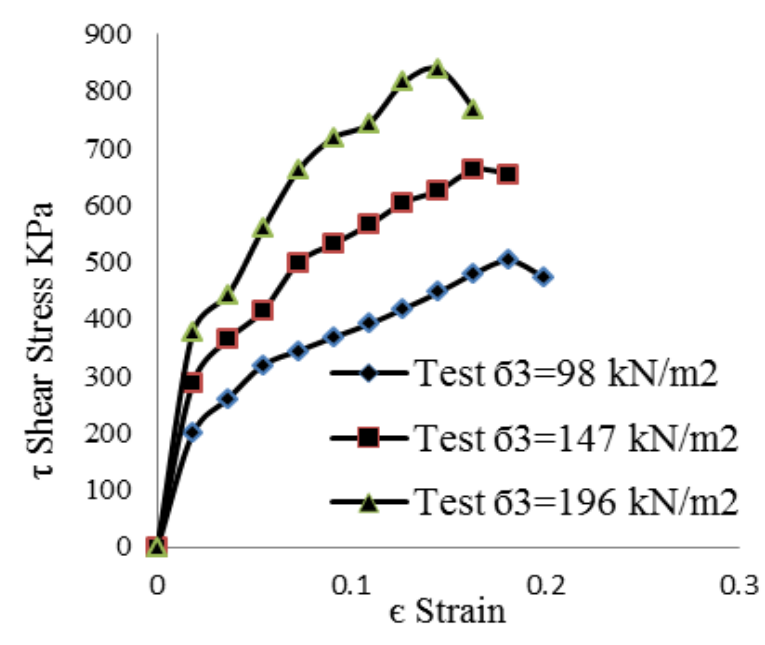

Fig 4; Stress Strain Curve from Triaxial Test of Soil

\subsection{Consolidation Test}

This test is completed to calculate the value and level of volume reduction that a horizontally confined soil sample undergoes when vertical load applied. From the calculated documents, the consolidation relation can be drowning. This document is very important to calculating the parameter index of compression, the re-compression index and the re-consolidation pressure of the soil. Figure 6 show the result of consolidation test. [7].

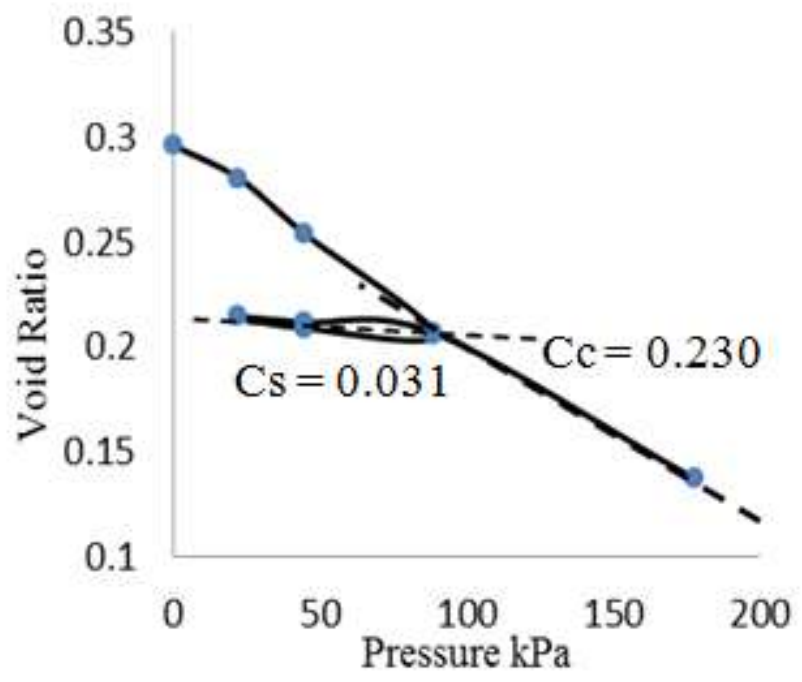

In addition to axial stress, axial and radiating strains may be estimating through the test, to calculated main elastic factors such as elastic Young's Modulus, E, and Poisson's ratio, $v$ and shear strength of soil (cohesive and internal soil friction). Figure 4 and 5 Show the result of test for three samples as shown in [7].

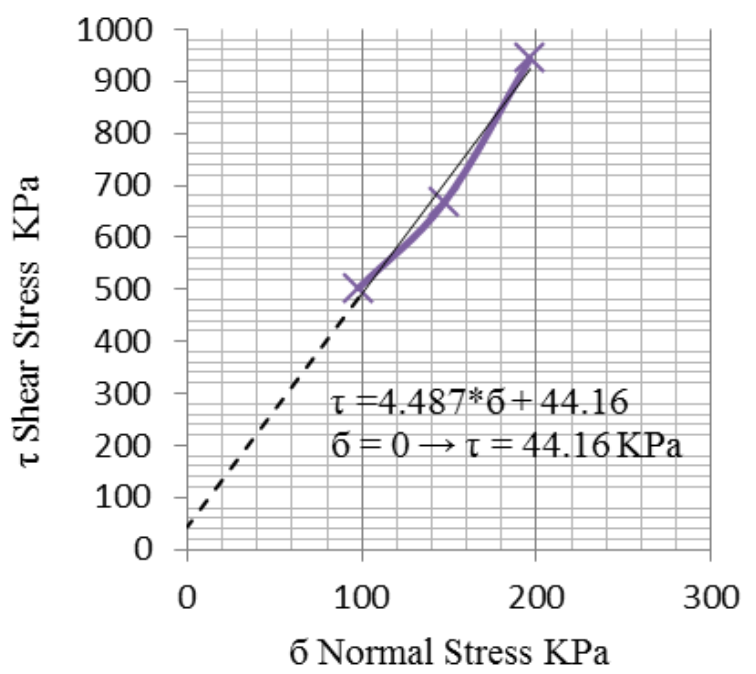

Fig.5; Soil Strength Parameter from Triaxial Test of Soil

\subsection{Shear Box Tests (Interface Tests)}

The interface shear box test is very important in the Geotechnical Engineering. A square plate represent shear box $(100 \mathrm{~mm} * 100 \mathrm{~mm})$ move laterally at middle-depth was used in contact with steel plate. Vertical stress is applied by adding dead loads on a hook, horizontal displacements are observed. Most importantly, the objective of the test was to estimate the mechanical properties of interface between clay soil and steel plate which represent the pile wall, Figure 7. [7].

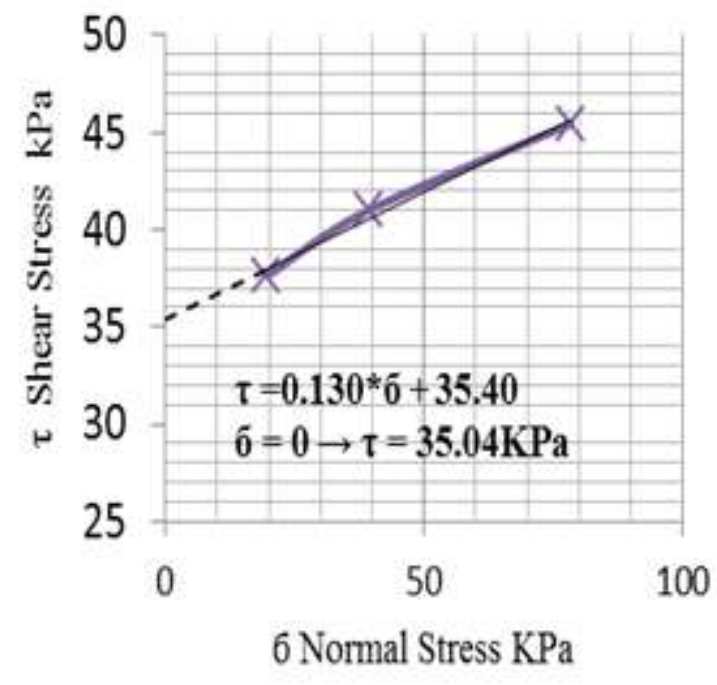

Fig 6; Consolidation Test for Soil Sample

Fig7; Shear and Normal Stress for Interface from Direct Shear Test 


\section{CAM CLAY PARAMETER}

Figure 8 shows the initial or past yield surface. The three means stresses computed above are marked on the diagram.
The maximum q value occurs where the yield surface passes through the CSL (critical state line), as it properly should. Figures 9 show the deviatoric relation with volumetric strain.

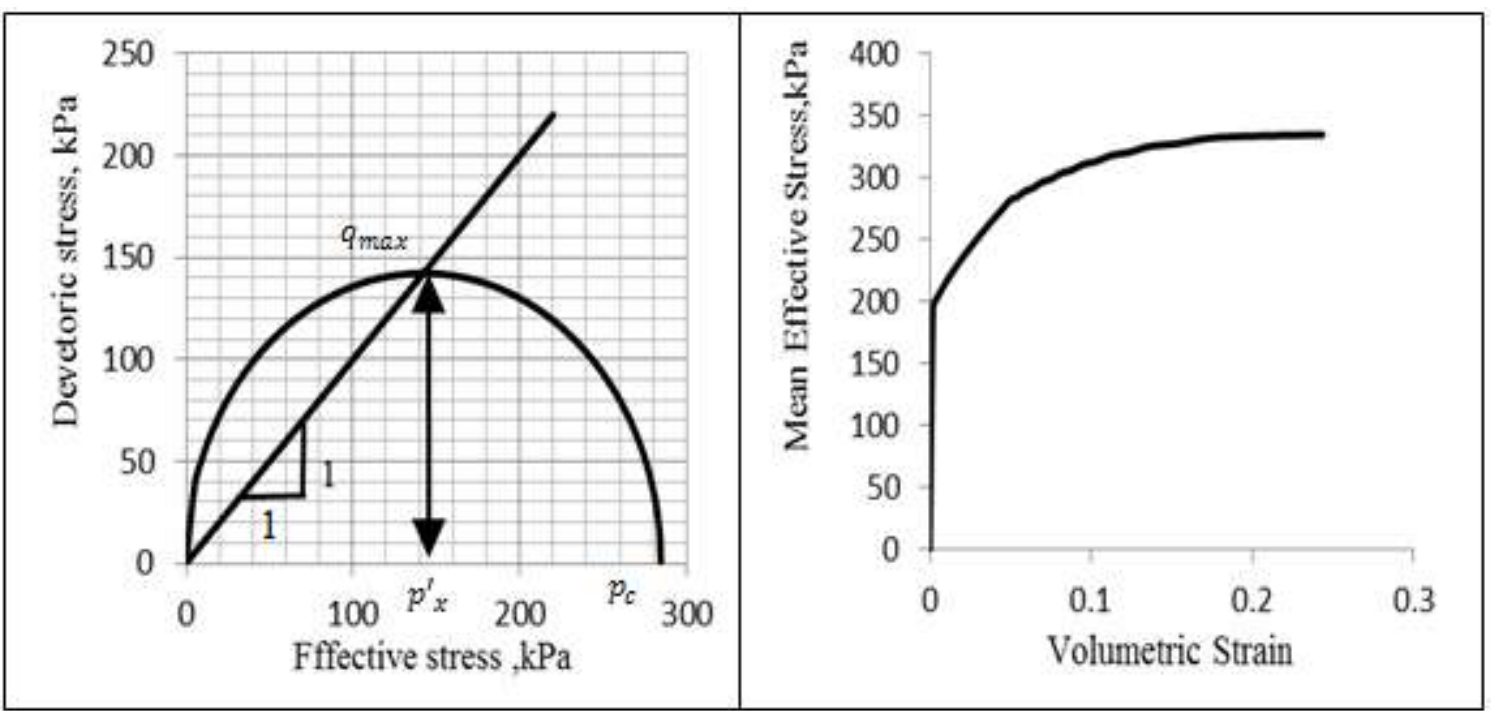

Fig 8; Initial Yield Surface for the Past Stresses

Fig 9; Mean Effective Stress Volumetric Strain Relationship

\section{DYNAMIC OF STRUCTURES}

The dynamic response of the offshore structure under regular wave is given below

$$
[M]\{\ddot{U}\}+[C]\{\dot{U}\}+[K]\{U\}=\{F\} \quad--4
$$

where $[\mathrm{M}]$ is the total mass matrix of the system, [ C] is the damping matrix, $[\mathrm{K}]$ is the structural stiffness matrix, $\{\mathrm{U}\}$ is the nodal displacements, $\{\mathrm{U}\}$ represent the nodal velocities, $\{\mathrm{U}\}$ represent the nodal accelerations, and $\{\mathrm{F}\}$ represent the hydrodynamic force [8].

\section{RESULTS AND DISCUSSION}

In this paper, Al-Amaya berthing dolphin figure 10 is take as a case study for wave loading in maximum direction (x-direction) by used Morison equation with physical properties calculated from Airy theory [9]. The variation in the resulted show the deck displacements at point A as shown in figure 10 for pile embedded in elastoplastic soft clay is large than the pile embedded elastic soft clay by $10 \%$ figure 11 , but the pile head displacement is increased from $1.9 \mathrm{~cm}$ for pile embedded in elastic soil model reach to $3.72 \mathrm{~cm}$ in elastoplastic condition due to reduce the domain stiffness of soil. The depth of pile fixity is increase about $35 \%$ from pile drive in elastic soil to the pile drive in elastoplastic soil figure 12 , for pile drive in the elastic soil the depth of pile fixity about 20 pile diameter and this ratio increased reach to 27 pile diameter for pile embedded in elastoplastic soil, while the bending moment is decreased about $10 \%$ figure 13 for same reason.

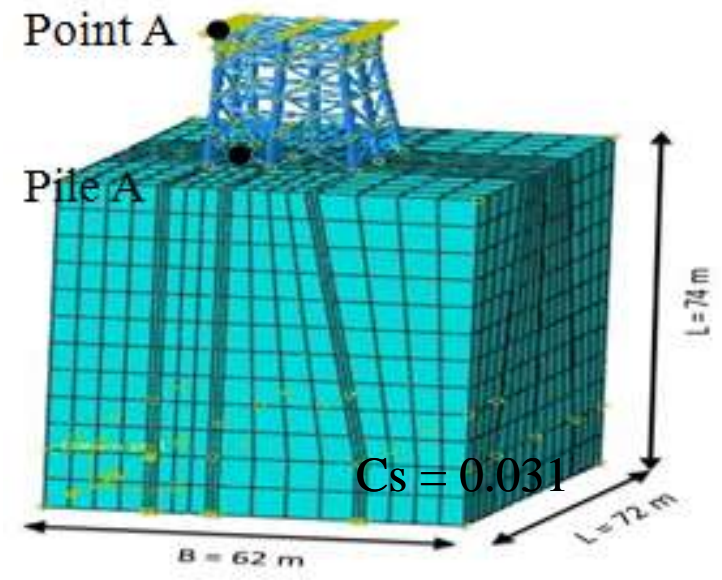

Fig.10; 3D Modeling of AL-Amaya Berthing Dolphin with ABAQUS

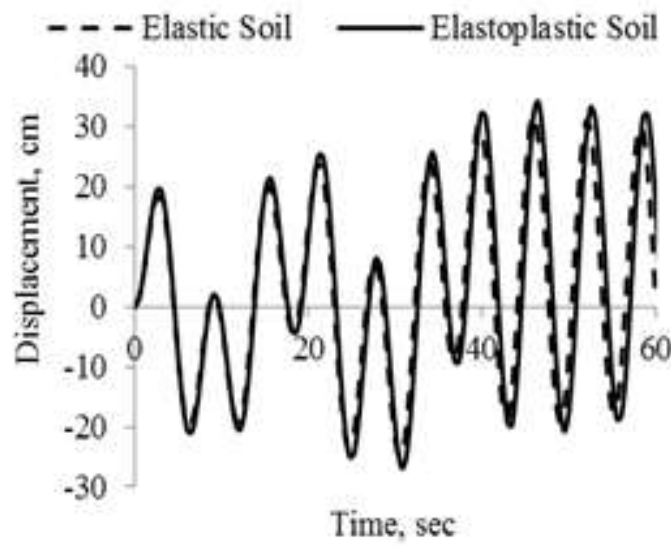

Fig 11; The Variation of Deck Displacement at Point A for Two Soil Models 


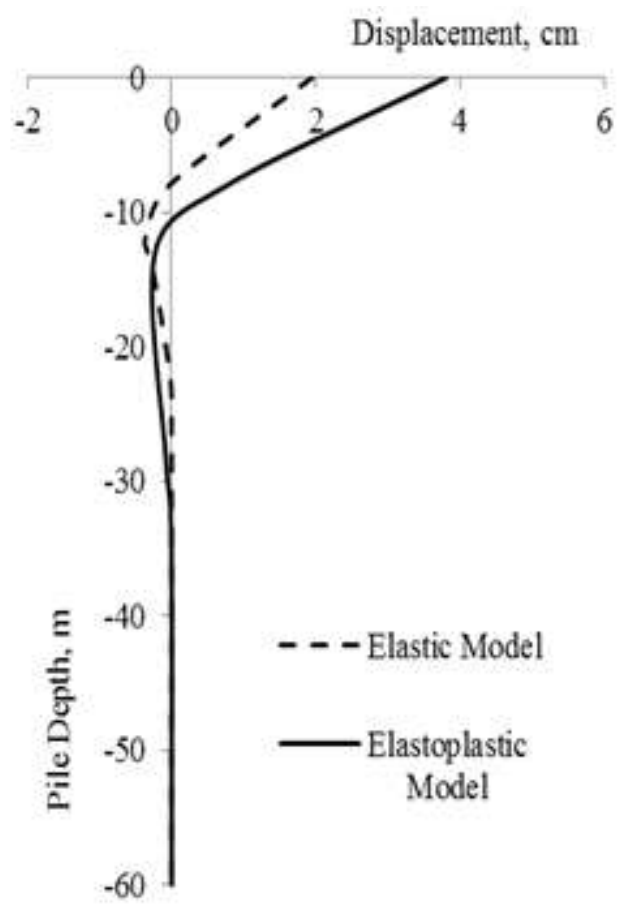

Fig 12; Pile Displacement at X-direction

\section{THE PROPOSED EQUATION FOR DEPTH OF}

\section{PILE FIXITY}

There is no relation obtained in previous studies for calculation the pile fixity depth in case of elastic and elastoplastic soil state respectively when pile subjected to moving loads, but there is relation for calculate approximately effective fixity depth of pile below the constant and moving loads built on analytical/semi-analytical techniques. The proposed equations are empirical formulas estimate the depth of pile fixity for soft clay. The recommended equation is depended on the following:

1- The elastic modulus and the moment of inertia of piles remain constant for elastic and elastoplastic soil model.

2- The interaction properties between the clay and steel pile, soil compressive strength, unchanged for elastic solution.

3- Soil properties are obtained by cam clay model for the elastoplastic model

$$
\begin{aligned}
& L f_{\text {elastic }}=0.43 *\left(\frac{E p I p}{C u}\right)^{0.31}--5 \\
& L f_{\text {plastic }}=0.54 *\left(\frac{E p I p}{C u}\right)^{0.31}--6
\end{aligned}
$$

Where

Lf elastic $=$ The Depth of Pile Fixity When Pile Embedded in Elastic Soil,

Lf Elastoplastic $=$ the Depth of Pile Fixity When Pile Embedded In Elastoplastic Soil,

$\mathrm{I}=$ Moment Of Inertia of Pile,

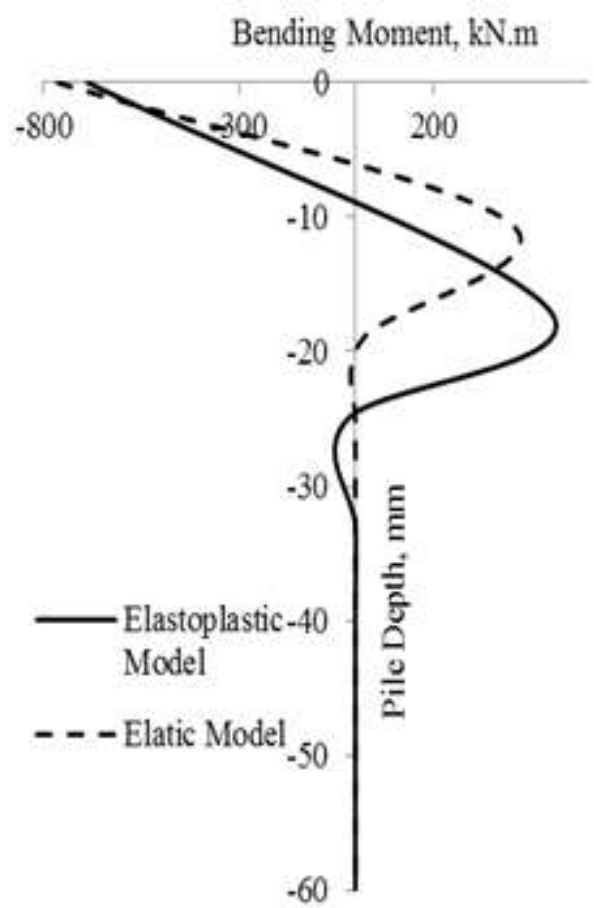

Fig 13; Pile Bending Moment

$\mathrm{Ep}=$ The Young's Modulus of Pile,

$\mathrm{Cu}=$ Cohesion between soil and clay from direct shear box test.

$0.43,0.54=$ Factors are founded from obtained results.

\section{CONCLUSION}

The main conclusion from this paper shows the dynamic structure response is increase by changing soil state from elastic to plastic, the deck displacement is small sensitive other than the pile head displacement for change soil state, the depth of pile fixity increased for elastoplastic soil model and the elastoplastic soil model is decrease the damping of structure.

\section{REFERENCES}

[1]. Scott A. Ashford, "Effect of Pile Diameter on the Modulus of Sub-Grade Reaction" Department of Structural Engineering University of California, San Diego La Jolla, California 92093-0085. 2005.

[2]. Chai, Y. H., and Hutchinson, T. C. (1999). "Flexural strength and ductility of reinforced concrete bridge piles." Final Report to Caltrans for Contract Number 59Y500, Report No. UCD-STR-99-2, Dept. of Civil \& Environmental Engineering, UC Davis, CA.

[3]. Reese L. C., and Van Impe W. F. "Single Pile and Pile Groups under Lateral Loading", London: Taylor \&Francis Group Plc, 2007.

[4]. Hibbitt, Karlsson and Sorensen Ins., ABAQUS User's Manual, Version 10.1, 2010.

[5]. D.J. Naylor, G. N. Pande, B. Simpson and R.Tabb. "Finite Elements in Geotechnical Engineering". Pineridge Press Swansea, U. K. 1981. 
[6]. David M. Wood. "Soil Behaviour and Critical State Soil Mechanics". Cambridge University Press. 1990.

[7]. BS5930. Code of Practice for Site Investigations. British Standards Institution, London.

[8]. C.A. Brebbia and S. Walker. "Dynamic Analysis of Offshore Structure". Butterworths \& Co. (publishers) Ltd, 1979

[9]. Sumer B. Mutlu and Jergen Fredsoe. "Hydrodynamic around Cylindrical Structure"s, Singapore: World Scientific Publishing, 2006. 